\title{
Review \\ How Can Malnutrition Affect Autophagy in Chronic Heart Failure? Focus and Perspectives
}

\author{
Giovanni Corsetti ${ }^{1} * \mathbb{C}^{0}$, Evasio Pasini ${ }^{2}$, Claudia Romano ${ }^{1}$, Carol Chen-Scarabelli ${ }^{3}$, Tiziano M. Scarabelli ${ }^{4}$, \\ Vincenzo Flati ${ }^{5}$, , Louis Saravolatz ${ }^{6}$ and Francesco S. Dioguardi ${ }^{7}$
}

1 Department of Clinical and Experimental Sciences, Division of Human Anatomy and Physiopathology, University of Brescia, 25123 Brescia, Italy; cla300482@gmail.com

2 Cardiac Rehabilitation Division, Scientific Clinical Institutes Maugeri (IRCCS), Lumezzane, 25065 Brescia, Italy; evpasini@gmail.com

3 Hunter Holmes McGuire Veterans Affairs Medical Centre (VAMC), Division of Cardiology, Richmond, VA 23249, USA; chenscarabelli@hotmail.com

4 Centre for Heart and Vessel Preclinical Studies at St. John Hospital and Medical Centre, Wayne State University, Detroit, MI 48202, USA; tscarabelli@hotmail.com

5 Department of Biotechnological and Applied Clinical Sciences, University of L'Aquila, 67100 L'Aquila, Italy; vincenzo.flati@univaq.it

6 Department of Medicine at St. John Hospital, Wayne State University, Detroit, MI 48202, USA; louis.saravolatz@ascension.org

7 Department of Internal Medicine, University of Cagliari, 09124 Cagliari, Italy; fsdioguardi@gmail.com

* Correspondence: giovanni.corsetti@unibs.it; Fax: +39-030-3717486

check for updates

Citation: Corsetti, G.; Pasini, E.; Romano, C.; Chen-Scarabelli, C.; Scarabelli, T.M.; Flati, V.; Saravolatz, L.; Dioguardi, F.S. How Can Malnutrition Affect Autophagy in Chronic Heart Failure? Focus and Perspectives. Int. J. Mol. Sci. 2021, 22, 3332. https://doi.org/10.3390/ ijms22073332

Academic Editor: Saša Frank

Received: 1 March 2021

Accepted: 21 March 2021

Published: 24 March 2021

Publisher's Note: MDPI stays neutral with regard to jurisdictional claims in published maps and institutional affiliations.

Copyright: (c) 2021 by the authors. Licensee MDPI, Basel, Switzerland. This article is an open access article distributed under the terms and conditions of the Creative Commons Attribution (CC BY) license (https:// creativecommons.org/licenses/by/ $4.0 /)$.

\begin{abstract}
Chronic heart failure (CHF) is a disease with important clinical and socio-economic ramifications. Malnutrition and severe alteration of the protein components of the body (protein disarrangements), common conditions in CHF patients, are independent correlates of heart dysfunction, disease progression, and mortality. Autophagy, a prominent occurrence in the heart of patients with advanced CHF, is a self-digestive process that prolongs myocardial cell lifespan by the removal of cytosolic components, such as aging organelles and proteins, and recycles the constituent elements for new protein synthesis. However, in specific conditions, excessive activation of autophagy can lead to the destruction of molecules and organelles essential to cell survival, ultimately leading to organ failure and patient death. In this review, we aim to describe the experimental and clinical evidence supporting a pathophysiological role of nutrition and autophagy in the progression of CHF. The understanding of the mechanisms underlying the interplay between nutrition and autophagy may have important clinical implications by providing molecular targets for innovative therapeutic strategies in CHF patients.
\end{abstract}

Keywords: malnutrition; autophagy; heart failure; chronic diseases; amino acids

\section{Chronic Diseases and Malnutrition: The Mortal Embrace}

Chronic diseases (CDs) are characterized by chronic inflammation with accompanying increased catabolism and reduced anabolism. This imbalance is also known as "hypercatabolic syndrome" (HCS). Although the pathophysiology of HCS is multi-factorial and nonhomogeneous, all CD patients display altered ratios between catabolic (e.g., TNF- $\alpha$, cortisol, catecholamine, glucagon, cytokines) and anabolic factors (e.g., insulin, insulin-like growth factors, and growth hormone). HCS severely impacts the body's metabolism, causing a disproportion between nutritional supply and energy demands as protein breakdown exceeds synthesis, leading to muscle wasting and cellular energy impairment with resultant alteration in protein turnover [1-4]. In addition, HCS promotes insulin resistance which, in turn, reduces protein synthesis and impairs metabolism, thus reinforcing the protein-amino acid disarrangement $[3,5]$. In patients, these metabolic conditions are related to worse 
clinical prognosis, increased mortality (independent of primary pathology), and increased health-related expenditure [6,7].

Among the CDs, chronic heart failure (CHF) is a pathology with a substantial impact on public health and public economic consumption. The factors leading to CHF can be grouped into four categories: (1) common risk factors such as hypertension, ischemic injury, metabolic syndrome; (2) genetic heart disease; (3) mechanical changes, such as valve dysfunction; and (4) immune-related causes, including infections (bacterial and viral) as well as autoimmune reactions [8]. Like in other CDs, CHF patients are characterized by high levels of inflammation [9], HCS with a decrease in body weight, sarcopenia (defined as loss of skeletal muscle and physical performance), and muscle wasting [10]. Clinically, these patients are often significantly malnourished as a nutritional intervention is frequently lacking or overlooked.

According to the World Health Organization, malnutrition is a condition defined as a supply/demand imbalance at the cellular level between the nutrients/energy intake and the organism's real demand for nutrients essential to ensure its correct development and maintenance [11]. This inadequate caloric and nutrient intake can lead to a decrease in muscle mass and immune system function with consequent deterioration in the quality of life, as demonstrated by a correlation between malnutrition and survival [12,13]. Malnutrition should be suspected by evaluation of the concentration of serum albumin $[2,12,14]$, with hypoalbuminemia (albumin values $<3 \mathrm{mg} / \mathrm{dL}$ ) considered to be the main marker of a poor nutritional status and an important prognosticator of increased morbidity and mortality in strokes [15] or after cardiovascular surgery [16].

In patients admitted for heart failure exacerbation, protein-energy malnutrition was associated with 2.5 times greater mortality, a 3-fold increase in cardiogenic shock, 1.5 times greater risk of acute kidney failure and respiratory failure, along with resultant increase in hospital length of stays and increased hospitalization costs [17].

Serum albumin deficiency is observed in about $30 \%$ of CHF patients [18], with or without concurrent anemia [10]. In addition to its association with higher in-hospital mortality rates in patients hospitalized with acute heart failure [19], including acute nonischemic heart failure [20], hypoalbuminemia is an independent predictor of long-term mortality in CHF patients $[19,21]$.

The impact of hypoalbuminemia on survival is not limited to heart failure with reduced ejection fraction as albumin levels were predictive of mortality in patients with heart failure with preserved ejection fraction [18]. Nonetheless, independent of admission albumin levels, in patients who improved albumin levels during hospitalization for acute decompensated heart failure, a lower risk of 1-year mortality and hospitalization was reported [22].

In CHF patients with severe muscle wasting, adequate protein-energy intake alone failed to improve nutritional and functional status. However, when adequate protein intake was supplemented with essential amino acids, improvements in exercise output, peak oxygen consumption, and walking test scores were observed [6].

It has been recently demonstrated that CHF patients have lower concentrations of amino acids (AAs), particularly essential AAs (EAAs), with an inverse relationship to heart failure severity [23]. Oral supplementation with branched-chain amino acids was found to improve serum albumin levels in hospitalized patients with heart failure [24].

The important role of serum albumin in the development of heart failure was underscored in a multicenter study of community-dwelling adults without heart failure: baseline hypoalbuminemia was associated with increased risk of incident heart failure during the 10-year follow-up [25].

In the body, muscle proteins and circulating proteins (albumin) comprise the major reservoir of AAs. In the presence of malnutrition, in an attempt to maintain the energy (via gluconeogenesis, or as intermediates of the Krebs cycle) and the appropriate level of AAs (mainly the EAAs) to meet the body's needs, the breakdown of muscle proteins occurs, thereby inducing sarcopenia $[2,12,26]$. Thus, in malnutrition, the reduction of 
caloric intake is not the main culprit responsible for tissue and organ damage. Indeed, it is interesting to note that, in mice models of qualitative malnutrition, it has been demonstrated that lifespan is inversely correlated with the percentage of non-EAAs (NEAAs) within the diet. Independent of the caloric intake, either mild limitation of EAAs intake or mild excess in NEAAs intake may induce permanent body consumption until death [27]. Pancreatic enzymes are responsible for the digestion of dietary proteins to obtain all AAs. However, the pancreas itself needs a large amount of AAs and energy to produce enzymes. Malnutrition and the hypercatabolic state may progressively reduce the efficiency of the pancreas and the mesenteric circulation, thereby impairing protein digestion and AA absorption [28]. Consequently, AA plasma concentrations decrease and may become insufficient to maintain protein synthesis and sustain energy requirements [3]. Unlike whole proteins, free AAs, provided through nutritional supplements, do not need to be digested; they are rapidly absorbed and therefore immediately available in the bloodstream for cellular uptake [3]. It has indeed been demonstrated that the availability of adequate dietary provision of all EAAs, in the correct stoichiometric proportion, is essential for the growth, development, health, and survival of animals $[27,29,30]$ and humans $[18,31]$.

\section{Nutritional Risk Assessment}

Nutritional index calculations have been studied as prognosticators of outcomes in heart failure. In a study of 1673 patients hospitalized with acute heart failure (either reduced or preserved ejection fraction), the prognostic nutritional index was independently associated with cardiovascular mortality and all-cause mortality [32]. The low prognostic nutritional index was also associated with higher in-hospital all-cause mortality and post-hospitalization 6-month mortality in elderly patients hospitalized with acute decompensated HF [33].

Similarly, in elderly patients hospitalized with heart failure with preserved ejection fraction (ejection fraction $\geq 50 \%$ ), a low geriatric nutritional risk index at discharge was predictive of all-cause mortality. Geriatric nutritional risk index predicts all-cause deaths in heart failure with preserved ejection fraction [34].

Malnutrition, as assessed by the Controlling Nutritional Status score on admission, was prognostic of long-term all-cause mortality in acute heart failure patients [35].

While most nutritional risk index calculators utilize serum albumin to assess the nutritional status of patients, the mini nutritional assessment screening tool may be used to identify elderly people at risk of malnutrition prior to any decline in serum albumin levels [36]. In heart failure patients in the outpatient setting, malnutrition assessed using the Mini Nutritional Assessment screening tool was predictive of mortality [37] and was an independent predictor of all-cause mortality or heart failure-related hospitalizations in outpatients with heart failure with mid-range ejection fraction [38].

\section{Autophagy}

Autophagy is a conserved cell quality control system, and increasing evidence suggests that it plays an important role in numerous and different biological processes, such as starvation, aging, inflammation, and organ remodeling, by maintaining cellular homeostasis. Autophagy occurs through the removal and degradation of intracellular components to recycle molecules needed for the synthesis of others. Three main types of autophagy have been identified: (1) macro-autophagy (commonly named autophagy), (2) micro-autophagy, and (3) chaperone-mediated autophagy. Macro-autophagy occurs by vesicle formation (autophagosome) to incorporate portions of the cytoplasm that then merge with lysosomes and result in digestion of the contents [39,40]. The presence of autophagy is demonstrated by the expression of autophagy-related proteins, such as light chain 3 (LC3), Beclin-1, autophagy-related gene (ATG), 5-12 complex, and p62 [41]. Micro-autophagy is also a degradation system that takes place directly on the surface of the lysosomes [42,43]. Finally, chaperone-mediated autophagy allows the selective degradation of only soluble proteins [40]. The prevalent function of autophagy is to promote cell survival in stressful 
conditions like starvation and preserve energy status in response to energy deprivation, hypoxic conditions, and high temperatures through digesting cellular components and recycling of essential elements for reuse [44,45]. Altered autophagy is also associated with many pathological states such as cancer, neurodegenerative disorders, myopathies, and cardiomyopathies [46].

\section{Autophagy in the Heart}

Autophagy in the heart occurs naturally at basal levels to maintain normal physiological cell functions [47]. However, it can be intensively activated in response to stressful situations such as decreased energy under the form of adenosine triphosphate (ATP) and increased oxidative stress, thus playing a pro-survival role [48]. During aging, although the rate of autophagosome formation and the efficiency of autophagosome-lysosome fusion as well as the proteolytic activity of lysosomes decline with age, continuous removal of exhausted or damaged components by efficient autophagy machinery, and their replacement with newly synthesized molecules, ensures cellular homeostasis and delays the aging process [48]. Indeed, it has been shown that lifelong caloric restriction by $40 \%$ increases the expression of autophagic markers in the heart [49]. The increase in autophagy resulting from caloric restriction may have a protective role on the cardiomyocytes by reducing levels of oxidative damage due to aging and cardiovascular diseases [50]. On the contrary, over-activated autophagy may deplete molecules and organelles fundamental for cellular survival, thus driving cells to death [51,52]. Autophagic degradation of "self" proteins for the production of AAs is also important for survival during neonatal starvation [53]. A state of nutrient deprivation, due to starvation or myocardial ischemia, induces autophagy, generating fatty acids and AAs that enter the Krebs cycle generating ATP and promoting survival of cardiac cells $[54,55]$. Although evidence indicates that physiological autophagy plays important roles in maintaining heart homeostasis, the excess of autophagy could favor and exacerbate heart-related diseases.

\section{Autophagy in Heart Failure}

Autophagy has been reported to play a role in the pathophysiology of human heart failure $[46,48,56]$. Many forms of heart failure are associated with the accumulation of misfolded proteins due to their impaired degradation and, hence, autophagy is fundamental under stress conditions like ischemia, starvation, and $\beta$-adrenergic stimulation, where it acts as a pro-survival mechanism by removing misfolded or anomalous proteins and damaged cellular structures [57].

Brief periods of ischemia may induce heart autophagy. In mouse hearts in vivo [54] and isolated rabbit hearts [58], autophagy was induced by ischemia and further enhanced by reperfusion. In hypoxic and re-perfused rabbit hearts, autophagosome formation has been observed after 20-40 $\mathrm{min}$ [59], and this is associated with functional myocyte recovery. More recently, it has been suggested that autophagy also enhances the survival of cardiomyocytes in hearts exposed to permanent coronary artery occlusion [60]. However, although many studies showed that induction of autophagy could preserve heart function during ischemia/reperfusion injury, others have suggested that autophagy contributes to cell death [41]. The magnitude of autophagy within the cell may contribute to its protective or detrimental role. Indeed, in human warm blood, cardioplegic arrest caused myocyte autophagy, with a magnitude and severity that were proportional to the length of cardioplegic arrest [61].

Autophagy has been recently extensively detected in patients with end-stage heart failure and precedes and sets the stage for the occurrence of apoptosis, oncosis, and necroptosis, which only rarely start independently of autophagy. The autophagic process progresses with broad cytosolic destruction and nuclear disintegration, finally resulting in cell death by necroptosis and, to a lesser extent, by apoptosis [62]. Then, autophagy seems to be a primary driving force leading to the progressive cardiomyocyte cell loss observed in 
end-stage heart failure [62]. It is interesting to note that the nucleus is the early autophagic target, and it develops typical erosions as if it had been caused by a bite (Figure $1 \mathrm{~A}-\mathrm{C}$ ).

In advanced stages of the autophagic process, the LC3-positive vacuoles develop TUNEL positivity, indicating that DNA fragments from the nucleus have been encapsulated within autophagosomes. These data are consistent with the possibility that autophagy is a primary driving force leading to progressive cardiac cell loss in end-stage heart failure [62]. The link between CD and CHF, malnutrition, HCS, and autophagy is schematized in Figure 2.
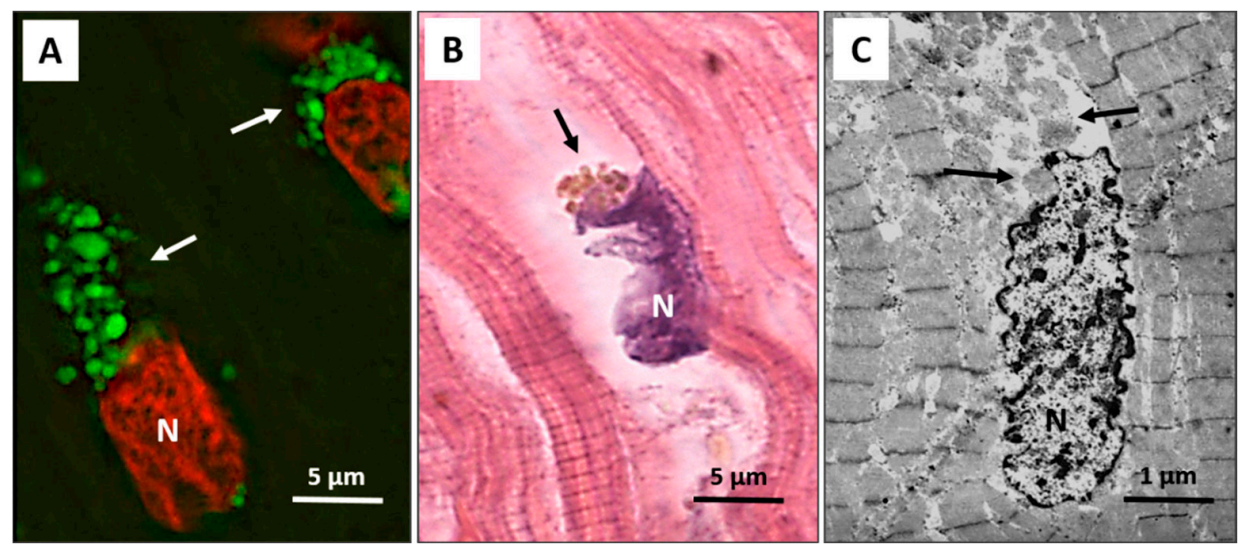

Figure 1. Failing heart. (A) Typical anti-LC3 immunofluorescence (green) of cardiomyocytes in an advanced stage of autophagic damage. Green bodies (arrows) are present around and much more at the pole of nuclei. Cardiomyocytes with massive green staining, in combination with the red staining of the nucleus, assume a "strawberry-like" appearance. $\mathrm{N}$ = nucleus in red; (B) Damaged cardiomyocytes show nuclei $(\mathrm{N})$ very irregular in shape as if he had been bitten. Around these nuclei, the cytoplasm is devoid of organelles, and there are always clumps of brown debris bodies (arrow) (eosin and hematoxylin staining); (C) Representative transmission electron microscopy pictures show a damaged cardiomyocyte, with chromatin condensation in the nucleus $(\mathrm{N})$ and deep invaginations of the nuclear envelope. Cytoplasmic granular material without organelles is present around the nucleus and near the nuclear pole (arrows).

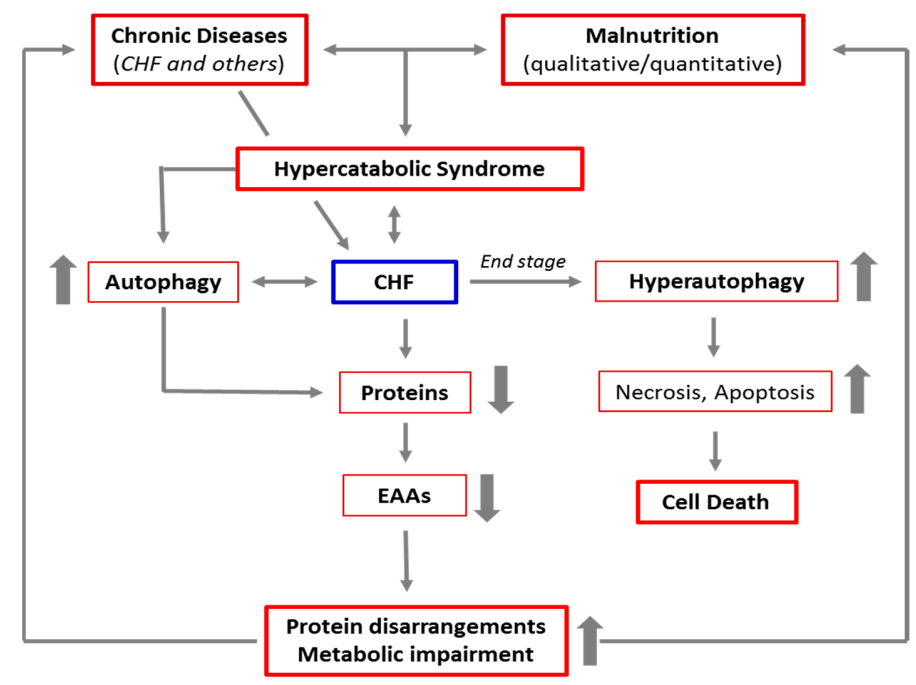

Figure 2. Schematic representation of the link between chronic diseases, malnutrition, hypercatabolic syndrome, and autophagy. The increase in catabolism induced by chronic diseases and malnutrition favors the activation of autophagy to guarantee the cells sufficient energy and materials to cope with accelerated metabolism. This results in a cascade of events, leading to protein disarrangements (the severe alteration of the protein components of the body), and then to metabolic impairment. This creates a vicious circle which, in the absence of adequate nutritional interventions, maintains and favors the hypercatabolic syndrome. Furthermore, in patients with advanced chronic diseases, like the end stage of $\mathrm{CHF}$, autophagy is severely triggered, and the autophagic machinery may also drive the cells to self-destruction. 
In specific conditions, excessive activation of autophagy can lead to the destruction of essential molecules and organelles favoring cell death [50,52] (autophagy-dependent cell death) with no signs of apoptosis or necrosis. This situation was recently named autosis [63].

\section{Role of Mammalian Target of Rapamycin (mTOR) in Autophagy}

Autophagy is a dynamic process that depends on strict coordination and regulation of multiple enzymatic pathways as Beclin-1/class III phosphatidylinositol-3 kinase (PI-3K), $\mathrm{PI}-3 \mathrm{~K} / \mathrm{Akt} / \mathrm{mTOR}$ pathways, and AMPK/mTOR. The last is directly influenced by the availability of nutrients, AAs in particular [64].

Usually, autophagy starts under conditions of energy deprivation in response to starvation with reduction of ATP synthesis. Adenosine monophosphate (AMP)-activated protein kinase (AMPK), an energy-sensing kinase, is activated when the concentration of ATP decreases. Under starvation (such as in ischemia or malnutrition), AMPK acts as a checkpoint by suppressing cellular growth and by promoting the activation of autophagy in cardiomyocytes. In fact, inhibition of AMPK reduces autophagy and increases cardiomyocyte cell death [55]. AMPK acts through ULK1 (Unc-51 like autophagy activating kinase) activation. In fact, ULK1 is a serine/threonine-protein kinase that mediates the induction of autophagy [65]. On the contrary, mTOR modulates autophagy by inhibiting the ULK1-kinase; it counteracts the activation of autophagy induced by AMPK. Thus, the AMPK-mTOR axis is crucial for the control of autophagy during energy stress and starvation [50]. On this basis, the excess of AMPK-induced autophagy, in a state of chronic disease or malnutrition, may be controlled by modulating mTOR activity.

mTOR is a highly conserved serine-threonine kinase that belongs to the PIKK (phosphoinositide 3-kinase related protein kinase) superfamily, which includes several kinases involved in nutrient sensing and DNA repair [66-68]. mTOR represents the crossroad of numerous biochemical pathways with functions that can be very different, sometimes even opposing each other. Its action, sometimes paradoxical, could be due to the fact that mTOR is the catalytic subunit of two distinct complexes: mTORC1 and mTORC2. mTORC1, localized on the outer membrane of lysosomes, and mTORC2, whose function requires association with ribosomes [69]. mTOR is activated by different stimuli, such as nutrients (nitrogen substrates provided by digestion of proteins or AAs), growth factors, energy and stress signals, and exercise. In response to these stimuli, mTORC1 mediates cell growth and proliferation. Then, mTOR acts as the center of a complex pathway network that controls protein synthesis, cell differentiation, growth, and proliferation [70-72]. In addition, energy variations and glucose availability are sensed by AMPK, which works coordinately with mTORC1 by shifting the cells to catabolic metabolism [73]. However, when AA availability is limited, mTOR can also operate through mTORC2 to promote autophagy [74]. Under these conditions, the role of mTORC1 shifts from suppressor to activator of autophagy, and the reactivation of mTOR is dependent on AAs one of the end products of autolysosomal degradation [75]. The different degrees of modulation of the mTORC1/mTORC2 complexes could shift a cell's fate from survival to death and vice-versa.

It has been shown that AAs and insulin stimulate translational control of protein synthesis but in different ways. Indeed, AAs do not activate phosphoinositide-3-kinase and protein kinase B (Akt) but stimulate mTOR indirectly through TSC1/2 (tuberous sclerosis 1 and 2 alias hamartin) downregulation and Rheb (Ras homolog enriched in brain) activation in skeletal muscle of aged animals [76]. It is interesting to note that mTOR is downregulated by treatment with AAs in elderly rat hearts [64]. AAs, as well as other nutrients and physical exercise, maintain anabolism by stimulating protein synthesis in skeletal and cardiac muscles through the phosphorylation of the ribosome-associated S6 kinase. This S6-kinase activation favors a high level of translation of mRNAs that encode ribosomal proteins, thus activating both cell entry of AAs and protein synthesis [77]. In addition, AAs repress autophagy by activating the mTOR (mTORC1-mediated) metabolic pathway $[29,64,78]$. 
Indeed, AAs are essential for mTORC1 activation. When there is nutrient availability, mTOR negatively regulates autophagy via mTORC1. On the contrary, in the setting of a deficiency of AAs, mTOR is not efficiently activated by other stimuli $[79,80]$ and can promote autophagy by operating through the mTORC2 complex [74]. The influence of AAs/nutrition, ATP/AMP, starvation, and caloric restriction on mTORC1 and autophagy is schematized in Figure 3.

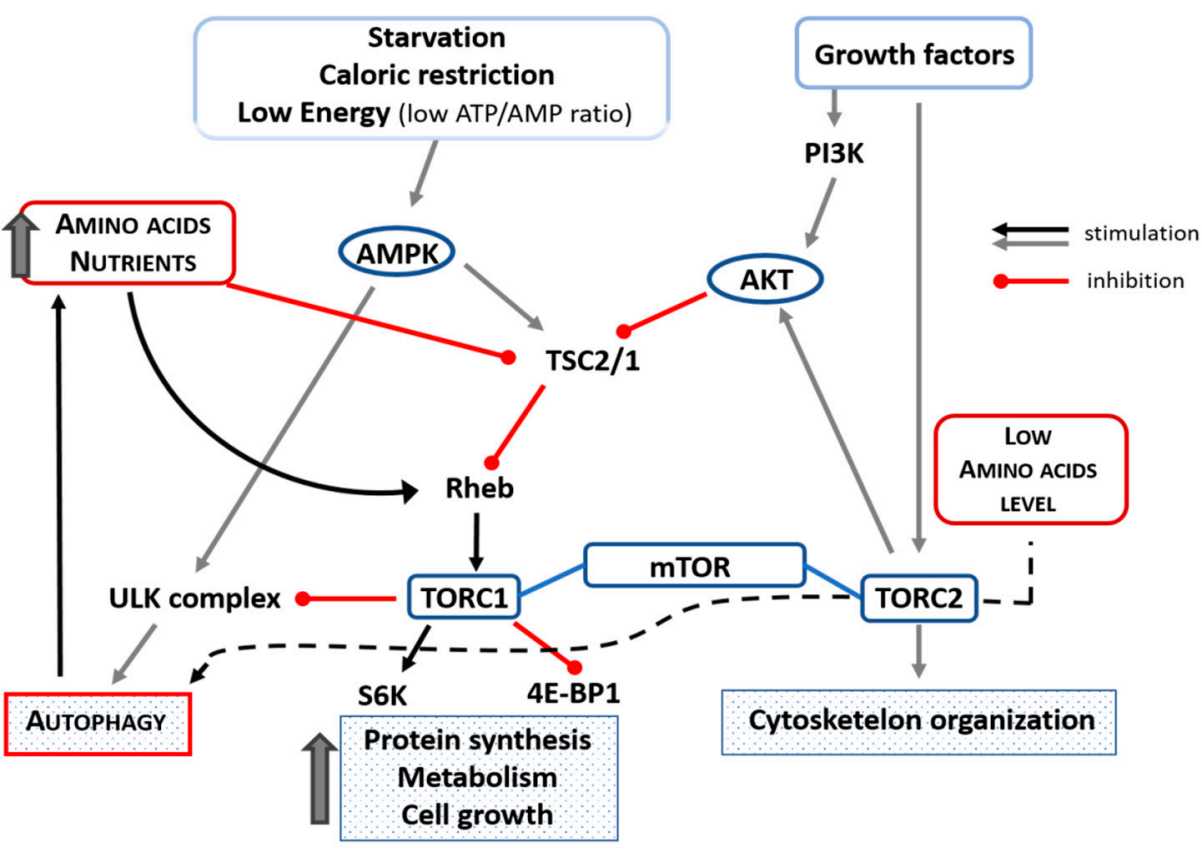

Figure 3. Schematic representation of the influence of amino acids, nutrients, starvation, low ATP/AMP ratio, and caloric restriction on mTORC1 and autophagy. Amino acid availability inhibits autophagy by inhibiting TSC2/1 and activating Rehb that could facilitate the transport of amino acids into the cell and which, in turn, could activate TORC1 that inhibits ULK-complex (black line). In case of low availability of amino acids, autophagy is activated through the TORC2 complex (black dotted line). Up thick arrow $=$ increase. Akt $=$ protein kinase B; ATP = adenosine triphosphate; 4EBP1 = eIF4E-binding protein-1; PI3K = phosphoinositide 3-kinase; Rheb = Ras homolog enriched in brain; S6 = S6-kinase; TSC1/2 = tuberous sclerosis complex 1/2; ULK (Unc-51 like autophagy activating kinase).

\section{The Use of EAAs in Treatment and Prevention of Malnutrition under Increased Metabolic Demand}

Muscle proteins and circulating proteins, constituting the reservoir of AAs in the body, are in continuous turnover. In normal conditions, daily protein metabolism by healthy individuals consists of 250-350 g of proteins, but under conditions of increased metabolic demand ( $\mathrm{CHF}$, senescence, chronic diseases, tumors, etc.), this amount rises dramatically.

The current recommended dietary allowance for protein intake deemed necessary to preserve muscle health is about $0.8 \mathrm{~g} / \mathrm{kg} /$ day [81-83]. However, people with acute or chronic diseases require a daily protein intake of at least $1.2-1.5 \mathrm{~g} / \mathrm{kg} /$ day $[82,84]$, whereas, in people with severe illnesses or overt malnutrition, the daily protein requirement increases to $2.0 \mathrm{~g} / \mathrm{kg} /$ day [83]. To cope with the continuous contraction, the heart has a very high metabolic demand and is able to "burn" any substrate (fatty acids, glucose, ketone bodies, and AAs) to obtain the necessary energy. Among these molecules, only the AAs are totipotent, capable of being transformed into other high-energy molecules (glucose and lipids) to produce ATP [2]. However, compared to fatty acids and glucose, AAs contribute to a lesser degree to ATP generation in the heart. Nevertheless, AAs, particularly the EAAs, play a pivotal role in cardiac function because they are fundamental for the synthesis of proteins, many of the metabolic and signaling intermediates, and many cofactors. It 
has been estimated that the mammalian heart renews all cellular components in about 30 days [85], thus underlining the huge demand for the availability of EAAs for protein and cofactor synthesis.

Under chronic disease states, especially $\mathrm{CHF}$, heart metabolism is chronically perturbed, resulting in an alteration of $\mathrm{Ca}^{2+}$ flux, generation of reactive oxygen species, energy deficiency and, finally, dysfunction of contractility. In this scenario, it seems logical to provide these patients with a suitable amount of all EAAs to stimulate anabolism and minimize autophagy of skeletal and cardiac muscles [18]. In elderly people, it has been demonstrated that muscles have reduced anabolic response to low doses of EAAs (below $10 \mathrm{~g} /$ day), whereas doses of about 10-15 g/day (with at least three g/day of L-leucine) induce protein synthesis comparable to that observed in younger adults [86]. As a consequence, it is strongly recommended that people with chronic diseases consume food rich in high-quality proteins with a higher amount of all EAAs or leucine-rich foods [87] or supplement their diet with an individualized stoichiometric mixture of all EAAs $[3,6]$.

\section{Perspectives}

The balance between anabolism and catabolism of muscle and visceral proteins is crucial to maintain body integrity and adequate metabolism as well as to maintain the contractile function of myocytes and cardiomyocytes. From the literature, it is clear that malnutrition and autophagy are closely related, especially in hypercatabolic conditions, to the heart.

The AAs, mainly the EAAs, are key molecules that provide the cells with the building blocks needed to build other molecules and cellular components. In addition, AAs enter the Krebs cycle [2], promoting anabolism, favoring mitochondrial biogenesis, and reducing hyperautophagy [29]. Clinical data from CHF patients suggest that diet, supplemented with specific blends of EAAs, counteracts the severe alteration of the protein components of the body (qualitative malnutrition) and cellular energy impairment without impairing kidney function $[88,89]$.

In light of this evidence, along with therapies recommended by good clinical practice (or clinical guideline-directed medical therapy), patients with CHF should be monitored to accurately evaluate their nutritional status and, if necessary, provided nutrients and EAAs in adequate quantities to counteract muscle hypercatabolism, malnutrition and cardiac damage resulting from hyperautophagy.

Author Contributions: Conceptualization, G.C., E.P. and T.M.S.; software, G.C. and C.R.; validation, F.S.D., T.M.S., C.C.-S. and L.S.; investigation, G.C., E.P. and C.R.; writing-original draft preparation, G.C., E.P. and C.R.; writing - review and editing, T.M.S., G.C., V.F. and C.C.-S.; supervision, F.S.D. and L.S.; project administration, G.C.; funding acquisition, G.C. All authors have read and agreed to the published version of the manuscript.

Funding: This research was funded by Dolomite-Franchi S.p.a. (Marone, Brescia, Italy) to G.C.

Institutional Review Board Statement: Not applicable.

Informed Consent Statement: Not applicable.

Data Availability Statement: Not applicable.

Conflicts of Interest: The authors declare that the research was conducted in the absence of any commercial or financial relationships that could be construed as a potential conflict of interest. The funders had no role in the design of the study; in the collection, analyses, or interpretation of data; in the writing of the manuscript; or in the decision to publish the results.

\section{References}

1. Tacke, M.; Ebner, N.; Boschmann, M.; Jarius, A.; Valentova, M.; Fülster, S.; Sandek, A.; Schomburg, L.; Anker, S.D.; Doehner, W.; et al. Resting Energy Expenditure and the Effects of Muscle Wasting in Patients with Chronic Heart Failure: Results from the Studies Investigating Comorbidities Aggravating Heart Failure (SICA-HF). J. Am. Med. Dir. Assoc. 2013, 14, 837-841. [CrossRef] [PubMed] 
2. Pasini, E.; Corsetti, G.; Aquilani, R.; Romano, C.; Picca, A.; Calvani, R.; Dioguardi, F.S. Protein-Amino Acid Metabolism Disarrangements: The Hidden Enemy of Chronic Age-Related Conditions. Nutrients 2018, 10, 391. [CrossRef] [PubMed]

3. Pasini, E.; Aquilani, R.; Dioguardi, F.; D'Antona, G.; Gheorghiade, M.; Taegtmeyer, H. Hypercatbolic syndrome: Molecular basis and effects of nutritional supplementation with aminoacids. Am. J. Cardiol. 2008, 101, S11-S15. [CrossRef]

4. Anker, S.D.; Chua, T.P.; Ponikowski, P.; Harrington, D.; Swan, J.W.; Kox, W.J.; Poole-Wilson, P.A.; Coats, A.J.S. Hormonal Changes and Catabolic/Anabolic Imbalance in Chronic Heart Failure and Their Importance for Cardiac Cachexia. Circulation 1997, 96, 526-534. [CrossRef]

5. Tremblay, F.; Lavigne, C.; Jacques, H.; Marette, A. Role of Dietary Proteins and Amino Acids in the Pathogenesis of Insulin Resistance. Annu. Rev. Nutr. 2007, 27, 293-310. [CrossRef]

6. Aquilani, R.; Opasich, C.; Dossena, M.; Iadarola, P.; Gualco, A.; Arcidiaco, P.; Viglio, S.; Boschi, F.; Verri, M.; Pasini, E. Increased skeletal muscle amino acid release with light exercise in deconditioned patients with heart failure. J. Am. Coll. Cardiol. 2005, 45, 158-160. [CrossRef]

7. Anker, S.D.; Ponikowski, P.; Varney, S.; Chua, T.P.; Clark, A.L.; Webb-Peploe, K.M.; Harrington, D.; Kox, W.J.A.; Poole-Wilson, P.; Coats, A.J. Wasting as independent risk factor for mortality in chronic heart failure. Lancet 1997, 349, 1050-1053. [CrossRef]

8. Dick, S.A.; Epelman, S. Chronic Heart Failure and Inflammation. Circ. Res. 2016, 119, 159-176. [CrossRef]

9. Heidenreich, P. Inflammation and heart failure: Therapeutic or diagnostic opportunity? J. Am. Coll. Cardiol. 2017, 69, 1286-1287. [CrossRef]

10. Aquilani, R.; Opasich, C.; Verri, M.; Boschi, F.; Febo, O.; Pasini, E.; Pastoris, O. Is nutritional intake adequate in chronic heart failure patients? J. Am. Coll. Cardiol. 2003, 42, 1218-1223. [CrossRef]

11. Alberda, C.; Graf, A.; McCargar, L. Malnutrition: Etiology, consequences, and assessment of a patient at risk. Best Pr. Res. Clin. Gastroenterol. 2006, 20, 419-439. [CrossRef]

12. Pasini, E.; Aquilani, R.; Gheorghiade, M.; Dioguardi, F.S. Malnutrition, muscle wasting and cachexia in chronic heart failure: The nutritional approach. Ital. Heart J. 2003, 4, 232-235.

13. Rondel, A.; Langius, J.; De Van Der Schueren, M.; Kruizenga, H. The new ESPEN diagnostic criteria for malnutrition predict overall survival in hospitalised patients. Clin. Nutr. 2018, 37, 163-168. [CrossRef] [PubMed]

14. Pasini, E.; Comini, L.; Dioguardi, F.S.; Grossetti, F.; Olivares, A.; Zanelli, E.; Aquilani, R.; Scalvini, S. Hypoalbuminemia as a marker of protein metabolism disarrangement in patients with stable chronic heart failure. Minerva Med. 2020, 111, 226-238. [CrossRef]

15. Gariballa, E.S.; Parker, S.G.; Taub, N.; Castleden, C.M. Influence of nutritional status on clinical outcome after acute stroke. Am. J. Clin. Nutr. 1998, 68, 275-281. [CrossRef]

16. Rady, M.Y.; Ryan, T.; Starr, N.J. Clinical Characteristics of Preoperative Hypoalbuminemia Predict Outcome of Cardiovascular Surgery. J. Parenter. Enter. Nutr. 1997, 21, 81-90. [CrossRef]

17. Adejumo, A.C.; Adejumo, K.L.; Adegbala, O.M.; Chinedozi, I.; Ndansi, J.; Akanbi, O.; Onyeakusi, N.E.; Ogundipe, O.A.; Bob-Manuel, T.; Adeboye, A. Protein-Energy Malnutrition and Outcomes of Hospitalizations for Heart Failure in the USA. Am. J. Cardiol. 2019, 123, 929-935. [CrossRef]

18. Liu, M.; Chan, C.-P.; Yan, B.P.; Zhang, Q.; Lam, Y.-Y.; Li, R.-J.; Sanderson, J.E.; Coats, A.J.; Sun, J.-P.; Yip, G.W.-K.; et al. Albumin levels predict survival in patients with heart failure and preserved ejection fraction. Eur. J. Heart Fail. 2012, 14, 39-44. [CrossRef]

19. Bonilla-Palomas, J.L.; Gámez-López, A.L.; Moreno-Conde, M.; López-Ibáñez, M.C.; Anguita-Sánchez, M.; De la Sacristana, Á.G.; García-Catalán, F.; Villar-Ráez, A. Hypoalbuminemia in Acute Heart Failure Patients: Causes and its Impact on Hospital and Long-Term Mortality. J. Card. Fail. 2014, 20, 350-358. [CrossRef]

20. Ancion, A.; Allepaerts, S.; Oury, C.; Gori, A.-S.; Piérard, L.A.; Lancellotti, P. Serum albumin level and hospital mortality in acute non-ischemic heart failure. ESC Heart Fail. 2017, 4, 138-145. [CrossRef]

21. Uthamalingam, S.; Kandala, J.; Daley, M.; Patvardhan, E.; Capodilupo, R.; Moore, S.A.; Januzzi, J.L. Serum albumin and mortality in acutely decompensated heart failure. Am. Heart J. 2010, 160, 1149-1155. [CrossRef]

22. Kato, T.; Yaku, H.; Morimoto, T.; Inuzuka, Y.; Tamaki, Y.; Ozasa, N.; Yamamoto, E.; Yoshikawa, Y.; Kitai, T.; Taniguchi, R.; et al Association of an increase in serum albumin levels with positive 1-year outcomes in acute decompensated heart failure: A cohort study. PLoS ONE 2020, 15, e0243818. [CrossRef]

23. Aquilani, R.; La Rovere, M.T.; Corbellini, D.; Pasini, E.; Verri, M.; Barbieri, A.; Condino, A.M.; Boschi, F. Plasma Amino Acid Abnormalities in Chronic Heart Failure. Mechanisms, Potential Risks and Targets in Human Myocardium Metabolism. Nutrients 2017, 9, 1251. [CrossRef]

24. Uchino, Y.; Watanabe, M.; Takata, M.; Amiya, E.; Tsushima, K.; Adachi, T.; Hiroi, Y.; Funazaki, T.; Komuro, I. Effect of Oral Branched-Chain Amino Acids on Serum Albumin Concentration in Heart Failure Patients with Hypoalbuminemia: Results of a Preliminary Study. Am. J. Cardiovasc. Drugs 2018, 18, 327-332. [CrossRef]

25. Filippatos, G.S.; Desai, R.V.; Ahmed, M.I.; Fonarow, G.C.; Love, T.E.; Aban, I.B.; Iskandrian, A.E.; Konstam, M.A.; Ahmed, A. Hypoalbuminaemia and incident heart failure in older adults. Eur. J. Heart Fail. 2011, 13, 1078-1086. [CrossRef]

26. Yin, J.; Lu, X.; Qian, Z.; Xu, W.; Zhou, X. New insights into the pathogenesis and treatment of sarcopenia in chronic heart failure. Theranostics 2019, 9, 4019-4029. [CrossRef]

27. Romano, C.; Corsetti, G.; Flati, V.; Pasini, E.; Picca, A.; Calvani, R.; Marzetti, E.; Dioguardi, F.S. Influence of Diets with Varying Essential/Nonessential Amino Acid Ratios on Mouse Lifespan. Nutrients 2019, 11, 1367. [CrossRef] 
28. Löhr, J.-M.; Panic, N.; Vujasinovic, M.; Verbeke, C.S. The ageing pancreas: A systematic review of the evidence and analysis of the consequences. J. Intern. Med. 2018, 283, 446-460. [CrossRef]

29. D'Antona, G.; Ragni, M.; Cardile, A.; Tedesco, L.; Dossena, M.; Bruttini, F.; Caliaro, F.; Corsetti, G.; Bottinelli, R.; Carruba, M.O.; et al. Branched-Chain Amino Acid Supplementation Promotes Survival and Supports Cardiac and Skeletal Muscle Mitochondrial Biogenesis in Middle-Aged Mice. Cell Metab. 2010, 12, 362-372. [CrossRef]

30. Corsetti, G.; Pasini, E.; Romano, C.; Calvani, R.; Picca, A.; Marzetti, E.; Flati, V.; Dioguardi, F.S. Body Weight Loss and Tissue Wasting in Late Middle-Aged Mice on Slightly Imbalanced Essential/Non-essential Amino Acids Diet. Front. Med. 2018, 5, 136. [CrossRef]

31. Ren, W.; Yin, Y.; Liu, G.; Yu, X.; Li, Y.; Yang, G.; Li, T.; Wu, G. Effect of dietary arginine supplementation on reproductive performance of mice with porcine circovirus type 2 infection. Amino Acids 2012, 42, 2089-2094. [CrossRef] [PubMed]

32. Cheng, Y.; Sung, S.; Cheng, H.; Hsu, P.; Guo, C.; Yu, W.; Chen, C. Prognostic Nutritional Index and the Risk of Mortality in Patients with Acute Heart Failure. J. Am. Heart Assoc. 2017, 6, e004876. [CrossRef] [PubMed]

33. Candeloro, M.; Di Nisio, M.; Balducci, M.; Genova, S.; Valeriani, E.; Pierdomenico, S.D.; Porreca, E. Prognostic nutritional index in elderly patients hospitalized for acute heart failure. ESC Heart Fail. 2020, 7, 2479-2484. [CrossRef] [PubMed]

34. Nishi, I.; Seo, Y.; Hamada-Harimura, Y.; Yamamoto, M.; Ishizu, T.; Sugano, A.; Sato, K.; Sai, S.; Obara, K.; Suzuki, S.; et al. Geriatric nutritional risk index predicts all-cause deaths in heart failure with preserved ejection fraction. ESC Heart Fail. 2019, 6, 396-405. [CrossRef]

35. Iwakami, N.; Nagai, T.A.; Furukawa, T.; Sugano, Y.; Honda, S.; Okada, A.; Asaumi, Y.; Aiba, T.; Noguchi, T.; Kusano, K.; et al. Prognostic value of malnutrition assessed by Controlling Nutritional Status score for long-term mortality in patients with acute heart failure. Int. J. Cardiol. 2017, 230, 529-536. [CrossRef]

36. Guigoz, Y.; Lauque, S.; Vellas, B.J. Identifying the elderly at risk for malnutrition. Clin. Geriatr. Med. 2002, 18, 737-757. [CrossRef]

37. Joaquín, C.; Puig, R.; Gastelurrutia, P.; Lupón, J.; De Antonio, M.; Domingo, M.; Moliner, P.; Zamora, E.; Martin, M.; Alonso, N.; et al. Mini nutritional assessment is a better predictor of mortality than subjective global assessment in heart failure out-patients. Clin. Nutr. 2019, 38, 2740-2746. [CrossRef]

38. Joaquín, C.; Alonso, N.; Lupón, J.; De Antonio, M.; Domingo, M.; Moliner, P.; Zamora, E.; Codina, P.; Ramos, A.; González, B.; et al. Mini Nutritional Assessment Short Form is a morbi-mortality predictor in outpatients with heart failure and mid-range left ventricular ejection fraction. Clin. Nutr. 2020, 39, 3395-3401. [CrossRef] [PubMed]

39. Shibutani, S.T.; Saitoh, T.; Nowag, H.; Münz, C.; Yoshimori, T. Autophagy and autophagy-related proteins in the immune system. Nat. Immunol. 2015, 16, 1014-1024. [CrossRef]

40. Cuervo, A.M.; Macian, F. Autophagy, nutrition and immunology. Mol. Asp. Med. 2012, 33, 2-13. [CrossRef]

41. Lin, X.; Xiao, W.; Xiao, L.; Liu, M. Molecular mechanisms of autophagy in cardiac ischemia/reperfusion injury (Review). Mol. Med. Rep. 2018, 18, 675-683. [CrossRef]

42. Li, W.-W.; Li, J.; Bao, J.-K. Microautophagy: Lesser-known self-eating. Cell. Mol. Life Sci. 2012, 69, 1125-1136. [CrossRef]

43. Feng, Y.; He, D.; Yao, Z.; Klionsky, D.J. The machinery of macroautophagy. Cell Res. 2014, 24, 24-41. [CrossRef]

44. Tsujimoto, Y.; Shimizu, S. Another way to die: Autophagic programmed cell death. Cell Death Differ. 2005, 12, 1528-1534. [CrossRef] [PubMed]

45. Denton, D.; Kumar, S. Autophagy-dependent cell death. Cell Death Differ. 2019, 26, 605-616. [CrossRef]

46. Kostin, S. Pathways of myocyte death: Implications for development of clinical laboratory biomarkers. Adv. Clin. Chem. 2005, 40, 37-98. [CrossRef] [PubMed]

47. Chiong, M.; Wang, Z.V.; Pedrozo, Z.; Cao, D.J.; Troncoso, R.E.; Ibacache, M.; Criollo, A.; Nemchenko, A.A.; Hill, J.; Lavandero, S. Cardiomyocyte death: Mechanisms and translational implications. Cell Death Dis. 2011, 2, e244. [CrossRef] [PubMed]

48. De Meyer, G.R.Y.; De Keulenaer, G.W.; Martinet, W. Role of autophagy in heart failure associated with aging. Heart Fail. Rev. 2010, 15, 423-430. [CrossRef]

49. Wohlgemuth, S.E.; Julian, D.; Akin, D.E.; Fried, J.; Toscano, K.; Leeuwenburgh, C.; Dunn, J.W.A. Autophagy in the Heart and Liver During Normal Aging and Calorie Restriction. Rejuvenation Res. 2007, 10, 281-292. [CrossRef]

50. Ahn, J.; Kim, J. Nutritional Status and Cardiac Autophagy. Diabetes Metab. J. 2013, 37, 30-35. [CrossRef]

51. Maiuri, M.C.; Zalckvar, E.; Kimchi, A.; Kroemer, G. Self-eating and self-killing: Crosstalk between autophagy and apoptosis. Nat. Rev. Mol. Cell Biol. 2007, 8, 741-752. [CrossRef]

52. Kroemer, G.; Levine, B. Autophagic cell death: The story of a misnomer. Nat. Rev. Mol. Cell Biol. 2008, 9, 1004-1010. [CrossRef]

53. Kuma, A.; Hatano, M.; Matsui, M.; Yamamoto, A.; Nakaya, H.; Yoshimori, T.; Ohsumi, Y.; Tokuhisa, T.; Mizushima, N. The role of autophagy during the early neonatal starvation period. Nat. Cell Biol. 2004, 432, 1032-1036. [CrossRef]

54. Matsui, Y.; Takagi, H.; Qu, X.; Abdellatif, M.; Sakoda, H.; Asano, T.; Sadoshima, J. Distinct roles of autophagy in the heart during ischemia and reperfusion: Roles of AMP-activated protein kinase and Beclin 1 in mediating autophagy. Circ. Res. 2007, 100, 914-922. [CrossRef]

55. Loos, B.; Lochner, A.; Engelbrecht, A.M. Autophagy in heart disease: A strong hypothesis for an untouched metabolic reserve. Med. Hypotheses 2011, 77, 52-57. [CrossRef]

56. Hein, S.; Arnon, E.; Kostin, S.; Schönburg, M.; Elsässer, A.; Polyakova, V.; Schaper, J. Progression from compensated hypertrophy to failure in the pressure-overloaded human heart: Structural deterioration and compensatory mechanisms. Circulation 2003, 107, 984-991. [CrossRef] 
57. Ghosh, R.; Pattison, J.S. Macroautophagy and Chaperone-Mediated Autophagy in Heart Failure: The Known and the Unknown. Oxid. Med. Cell. Longev. 2018, 2018, 8602041. [CrossRef]

58. Decker, R.S.; Wildenthal, K. Lysosomal alterations in hypoxic and reoxygenated hearts. I. Ultrastructural and cytochemical changes. Am. J. Pathol. 1980, 98, 425-444.

59. Liu, X.; Van Vleet, T.; Schnellmann, R.G. The role of calpain in oncotic cell death. Annu. Rev. Pharmacol. Toxicol. 2004, 44, 349-370. [CrossRef]

60. Zhang, Z.; Li, H.; Chen, S.; Li, Y.; Cui, Z.; Ma, J. Knockdown of microRNA-122 protects H9c2 cardiomyocytes from hypoxiainduced apoptosis and promotes autophagy. Med. Sci. Monit. 2017, 23, 4284-4290. [CrossRef]

61. Chen-Scarabelli, C.; Faggian, G.; Shah, M.; Saravolatz, L., II; Saravolatz, S.; Scarabelli, G.; Scarabelli, T.M. Warm blood cardioplegia induces myocyte autophagy, whose magnitude and severity are proportional to the duration of cardioplegic arrest. Circulation 2010, 122, A142.

62. Corsetti, G.; Chen-Scarabelli, C.; Romano, C.; Pasini, E.; Dioguardi, F.S.; Onorati, F.; Knight, R.; Patel, H.; Saravolatz, L.; Faggian, G.; et al. Autophagy and Oncosis/Necroptosis Are Enhanced in Cardiomyocytes from Heart Failure Patients. Med. Sci. Monit. Basic Res. 2019, 25, 33-44. [CrossRef]

63. Liu, Y.; Shoji-Kawata, S.; Sumpter, R.M.; Wei, Y.; Ginet, V.; Zhang, L.A.; Posner, B.; Tran, K.A.; Green, D.R.; Xavier, R.J.; et al. Autosis is a $\mathrm{Na}+, \mathrm{K}+$-ATPase-regulated form of cell death triggered by autophagy-inducing peptides, starvation, and hypoxia-ischemia. Proc. Natl. Acad. Sci. USA 2013, 110, 20364-20371. [CrossRef]

64. Kim, J.; Kundu, M.; Viollet, B.; Guan, K.-L. AMPK and mTOR regulate autophagy through direct phosphorylation of Ulk1. Nat. Cell Biol. 2011, 13, 132-141. [CrossRef]

65. Morita, M.; Gravel, S.-P.; Hulea, L.; Larsson, O.; Pollak, M.; St-Pierre, J.; Topisirovic, I. mTOR coordinates protein synthesis, mitochondrial activity and proliferation. Cell Cycle 2015, 14, 473-480. [CrossRef]

66. Albert, V.; Hall, M.N. mTOR signaling in cellular and organismal energetics. Curr. Opin. Cell Biol. 2015, 33, 55-66. [CrossRef]

67. Howell, J.J.; Manning, B.D. mTOR couples cellular nutrient sensing to organismal metabolic homeostasis. Trends Endocrinol. Metab. 2011, 22, 94-102. [CrossRef]

68. Flati, V.; Corsetti, G.; Pasini, E.; Rufo, A.; Romano, C.; Dioguardi, F.S. Nutrition, Nitrogen Requirements, Exercise and Chemotherapy-Induced Toxicity in Cancer Patients. A Puzzle of Contrasting Truths? Anti Cancer Agents Med. Chem. 2015, 16, 89-100. [CrossRef]

69. Nijhout, H.F.; Callier, V. A new mathematical approach for qualitative modeling of the insulin-TOR-MAPK network. Front. Physiol. 2013, 4, 245. [CrossRef]

70. Evans, D.S.; Kapahi, P.; Hsueh, W.-C.; Kockel, L. TOR signaling never gets old: Aging, longevity and TORC1 activity. Ageing Res. Rev. 2011, 10, 225-237. [CrossRef]

71. Navé, B.T.; Ouwens, M.; Withers, D.J.; Alessi, D.R.; Shepherd, P.R. Mammalian target of rapamycin is a direct target for protein kinase B: Identification of a convergence point for opposing effects of insulin and amino-acid deficiency on protein translation Biochem. J. 1999, 344, 427-431. [CrossRef]

72. Mihaylova, M.M.; Shaw, R.J. The AMPK signalling pathway coordinates cell growth, autophagy and metabolism. Nat. Cell Biol. 2011, 13, 1016-1023. [CrossRef]

73. Yu, L.; McPhee, C.K.; Zheng, L.; Mardones, G.A.; Rong, Y.; Peng, J.; Mi, N.; Zhao, Y.; Liu, Z.; Wan, F.; et al. Termination of autophagy and reformation of lysosomes regulated by mTOR. Nature 2010, 465, 942-946. [CrossRef]

74. Deldicque, L.; Theisen, D.; Francaux, M. Regulation of mTOR by amino acids and resistance exercise in skeletal muscle. Graefes Arch. Clin. Exp. Ophthalmol. 2005, 94, 1-10. [CrossRef]

75. Proud, C.G. mTOR-mediated regulation of translation factors by amino acids. Biochem. Biophys. Res. Commun. 2004, 313, 429-436 [CrossRef]

76. Flati, V.; Pasini, E.; D'Antona, G.; Speca, S.; Toniato, E.; Martinotti, S. Intracellular Mechanisms of Metabolism Regulation: The Role of Signaling via the Mammalian Target of Rapamycin Pathway and Other Routes. Am. J. Cardiol. 2008, 101, S16-S21. [CrossRef]

77. Hara, K.; Yonezawa, K.; Weng, Q.-P.; Kozlowski, M.T.; Belham, C.; Avruch, J. Amino Acid Sufficiency and mTOR Regulate p70 S6 Kinase and eIF-4E BP1 through a Common Effector Mechanism. J. Biol. Chem. 1998, 273, 14484-14494. [CrossRef]

78. Wang, X.; Campbell, L.E.; Miller, C.M.; Proud, C.G. Amino acid availability regulates p70 S6 kinase and multiple translation factors. Biochem. J. 1998, 334, 261-267. [CrossRef]

79. Volpi, E.; Campbell, W.W.; Dwyer, J.T.; Johnson, M.A.; Jensen, G.L.; Morley, J.E.; Wolfe, R.R. Is the optimal level of protein intake for older adults greater than the rec-ommended dietary allowance? J. Gerontol. A Biol. Sci. Med. Sci. 2013, 68, 677-681. [CrossRef] [PubMed]

80. Morley, J.E.; Argiles, J.M.; Evans, W.J.; Bhasin, S.; Cella, D.; Deutz, N.E.; Doehner, W.; Fearon, K.C.; Ferrucci, L.; Hellerstein, M.K.; et al. Nutritional Recommendations for the Management of Sarcopenia. J. Am. Med. Dir. Assoc. 2010, 11, 391-396. [CrossRef] [PubMed]

81. Bauer, J.; Biolo, G.; Cederholm, T.; Cesari, M.; Cruz-Jentoft, A.J.; Morley, J.E.; Phillips, S.; Sieber, C.; Stehle, P.; Teta, D.; et al. Evidence-Based Recommendations for Optimal Dietary Protein Intake in Older People: A Position Paper from the PROT-AGE Study Group. J. Am. Med. Dir. Assoc. 2013, 14, 542-559. [CrossRef] 
82. Paddon-Jones, D.; Short, K.R.; Campbell, W.W.; Volpi, E.; Wolfe, R.R. Role of dietary protein in the sarcopenia of aging. Am. J. Clin. Nutr. 2008, 87, S1562-S1566. [CrossRef]

83. Sud, M.; Wang, X.; Austin, P.C.; Lipscombe, L.L.; Newton, G.E.; Tu, J.V.; Vasan, R.S.; Lee, U.S. Presentation blood glucose and death, hospitalization, and future diabetes risk in patients with acute heart failure syndromes. Eur. Heart J. 2015, 36, 924-931. [CrossRef]

84. Katsanos, C.S.; Kobayashi, H.; Sheffield-Moore, M.; Aarsland, A.; Wolfe, R.R. Aging is associated with diminished accretion of muscle proteins after the ingestion of a small bolus of essential amino acids. Am. J. Clin. Nutr. 2005, 82, 1065-1073. [CrossRef] [PubMed]

85. Martone, A.M.; Marzetti, E.; Calvani, R.; Picca, A.; Tosato, M.; Santoro, L.; Di Giorgio, A.; Nesci, A.; Sisto, A.; Santoliquido, A.; et al. Exercise and Protein Intake: A Synergistic Approach against Sarcopenia. BioMed Res. Int. 2017, 2017, 2672435. [CrossRef] [PubMed]

86. Aquilani, R.; Viglio, S.; Iadarola, P.; Opasich, C.; Testa, A.; Dioguardi, F.S.; Pasini, E. Oral Amino Acid Supplements Improve Exercise Capacities in Elderly Patients with Chronic Heart Failure. Am. J. Cardiol. 2008, 101, S104-S110. [CrossRef]

87. Aquilani, R.; Opasich, C.; Gualco, A.; Verri, M.; Testa, A.; Pasini, E.; Viglio, S.; Iadarola, P.; Pastoris, O.; Dossena, M.; et al. Adequate energy-protein intake is not enough to improve nutritional and metabolic status in muscle-depleted patients with chronic heart failure. Eur. J. Heart Fail. 2008, 10, 1127-1135. [CrossRef]

88. Scognamiglio, R.; Testa, A.; Aquilani, R.; Dioguardi, F.S.; Pasini, E. Impairment in walking capacity and myocardial function in the elderly: Is there a role for non-pharmacologic therapy with nutritional amino acid supplementation? Am. J. Cardiol. 2008, 101, S78-S81. [CrossRef]

89. Vlahakis, A.; Powers, T. A role for TOR complex 2 signaling in promoting autophagy. Autophagy 2014, 10, 2085-2086. [CrossRef] 